\title{
Secure Clamping of Parts for Disassembly for Remanufacturing
}

\author{
Simon Rieß, Jonas Wiedemann, Sven Coutandin \\ and Jürgen Fleischer
}

\begin{abstract}
Robot based remanufacturing of valuable products is commonly perceived as promising field in future in terms of an efficient and globally competitive economy. Additionally, it plays an important role with regard to resource-efficient manufacturing. The associated processes however, require a reliable non-destructive disassembly. For these disassembly processes, there is special robot periphery essential to enable the tasks physically. Unlike manufacturing, within remanufacturing there are End-of-Life (EoL) products utilized. The specifications and conditions are often uncertain and varying. Consequently the robot system and especially the periphery needs to adapt to the used product, based on an initial examination and classification of the part. State of the art approaches provide limited flexibility and adaptability to the disassembly of electric motors used in automotive industry. Especially the geometrical shape is a limiting factor for using state of the art periphery for remanufacturing. Within this contribution a new kind of flexible clamping device for the disassembly of EoL electrical motors is presented. The robot periphery is systematically developed
\end{abstract}

S. Rieß ( $₫) \cdot J$. Wiedemann $\cdot$ S. Coutandin $\cdot$ J. Fleischer

Karlsruhe Institute of Technology, 76131 Karlsruhe, BW, Germany

e-mail: simon.riess@kit.edu

J. Wiedemann

e-mail: jonas.wiedemann@student.kit.edu

S. Coutandin

e-mail: sven.coutandin@kit.edu

J. Fleischer

e-mail: juergen.fleischer@kit.edu

T. Schüppstuhl et al. (eds.), Annals of Scientific Society for Assembly,

Handling and Industrial Robotics 2021,

https://doi.org/10.1007/978-3-030-74032-0_7 
regarding the requirements stemming from the remanufacturing approach. It consists of three clamping units with moveable pins. Utilizing two linear axes, a two dimensional working space is realized for clamping the parts depending on their conditions and shape.

\section{Keywords}

Clamping System $\cdot$ Disassembly $\cdot$ Remanufacturing

\section{Introduction}

Circular economy and remanufacturing as part of it has dragged a lot of attention within the last years. It is expected, that the numerous advantages will lead to an increased number of realized remanufacturing solutions in future Tolio et al. [1]. Among the advantages, there are fewer investments for manufacturers in producing and selling a product [2], less energy consumption during production and a smaller environmental impact [3]. However, there are some major challenges to overcome for the realization and operating of remanufacturing production lines. After assembly and during its life cycle, products naturally underlie changes and physical effects. Therefore the products appear with alterations after their lives at the remanufacturing line. Products are referred to be of unknown specifications upon feeding into the remanufacturing production system. Consequently, today's remanufacturing lines include human labor to handle the uncertainties with human intuition [4]. To be economically competitive on the other hand, industry has an interest to automate the remanufacturing process. Automating processes with a high number of product variations demands a high flexibility from the production system [5]. Handling devices and utilized machine equipment need to fit the processed products. This contribution presents a clamping system for fixation of parts for disassembly operations. The novelty of the system is the application of reconfigurable support modules in the domain of disassembly for remanufacturing of electric motors. Due to the adaptability of the clamping system, a high flexibility regarding product variations is realized. The clamping system is presented in a CAD model and a functional prototype, which proves the functionality of the approach.

\section{Current State of the Art of Clamping Devices in Disassembly for Remanufacturing Applications}

Many of today's products are not designed for remanufacturing or disassembly, but for their usage within the life-cycles [6]. Consequently, disassembly for remanufacturing is rather complicated to realize. For example, hardly reachable connections, certain fastening and assembly principles, surface coatings and untracked influences during the life-cycle 
on the connections complicate the dismantling. At the same time, the disassembly step is considered as one of the key challenges to realize for its direct influence on the subsequent re-assembly of the product. The relevant connectors need to be dismantled in such a way, that following process steps need not rework the connection leading to additional expenses and thus a minimization of the economic benefit [7]. During the dismantling of connectors, there are physical process forces occurring which need to be taken into account. Therefore a fixation of the part is mandatory. In industry, different kinds of grippers and clamping systems are used. In academia, there is research being conducted to develop adequate gripping and clamping systems. The following paragraph gives a summarizing overview of related work.

The current state of the art of industrial clamping devices for remanufacturing applications has a twofold character on the level of flexibility. On the one end of the spectrum, there are automated disassembly systems which are typically capable of processing a small spectrum of products and provide limited adaptability towards different products. Typical examples can be found in the disassembly of mobile phones or single use cameras $[8,9]$. Utilized clamping devices are thus specially designed tools covering a small number of product derivatives and product variations. On the other end of the spectrum, there are disassembly systems with a rather large degree of flexibility based on manual labor. Examples are to be found in the disassembly for remanufacturing in gearbox remanufacturing [10]. Utilized clamping devices for disassembly are typically manually actuated clamping vices with the human deciding on the best clamping position, orientation and forces. Because of the mandatory flexibility, clamping devices have been subject to intensive research efforts. In an early work, until then existing optimizations methods for the selection of support positions in fixture designs are summarized by Menassa and DeVries [11]. It is found, that kinematic analysis from CAD simulations and finite element analysis can solve the problem appropriately, given the processing forces. In a more recent contribution, Kaya optimizes the layout of a fixture system with the aid of genetic algorithms [12]. It is thus possible to solve fixture layout problems with regard to previously defined process forces from a simulation. The adaption of clamping systems to the physical shape of the product is a related question also. The state of the research tackles this question by reconfigurable systems. There are systems which can configure towards different geometrical shapes. The contribution of Jonsson et al. serves as example [13]. In this contribution, there are multiple fixture elements being placed on a rig depending on the operations. After one part has been processed, the clamping system may be reconfigured for different parts. Another work by Brost and Peters studies the automated design of 3-D fixtures [14]. With the developed pin board tool, arbitrarily shaped parts can be clamped on a planar surface and the system may be reconfigured afterwards. Modern trends in the design of clamping layouts can be summarized to active fixturing [15]. Clamping devices of this kind are equipped with elements, which modify the applied forces on the part with respect to variable inputs. A representative contribution is the work of Valisek et al. Within this contribution, a pneumatic clamping device equipped with 
multiple sensors is developed [16]. Summarizing the state of the art one can say that many solutions for the clamping of parts in different applications exist and related questions were answered. Clamping systems in disassembly for remanufacturing applications in special have not been subject to research however. Thus existing solutions for the configuration towards different parts which are subject to external influences during their lifecycles has not been regarded. Especially for the use case of automated disassembly of electric motors, a clamping system is required.

\section{Concept of the Clamping System for Disassembly for Remanufacturing}

\subsection{Extracting Requirements}

Functional requirements are extracted from the analysis of the state of the art and explained in detail below. The given list is may not be complete for all disassembly tasks. It sums up the requirements for manipulation tasks for the remanufacturing of electrical motors. Different use cases may have special requirements.

1. Processing of multiple part derivatives on same remanufacturing production system

As discussed, economically operated remanufacturing lines need to adapt physically to multiple product derivatives. This is because of the assumption, that multiple products are being processed on one solely remanufacturing line. Correspondingly, the clamping devices need to be of such kind to enable the clamping despite the possible physical variations of derivatives. One possible solution is the configuration of clamping elements to different products by adaptive clamping elements.

2. Reliable adaption of clamping unit to uncertain classification of parts

Even in case of an ambiguous, vague or an erroneous classification of parts, the fixation of the part has to be reliable. If such a fixation cannot be realized, the clamping system needs to report this information to the higher control device. In the best case, the clamping device is capable of sensing critical data, to improve the classification.

3. Withstand process forces without irreversible distortion and appropriate clamping forces to enable dismantling process without damaging the core at the same time

The clamping device has to withstand the applied process forces. Therefore, the mechanical structure needs to be of a solid construction. Applied clamping forces need to be large enough to enable the dismantling of the product. Yet at the same time, they cannot exceed the physical limits of the part, leaving irreversible damages. 
4. Exposition of connectors to handling device for dismantling

In order to expose the areas of interest to other handling devices, the positioning and orientation of the part within the clamping device needs to be planned. Therefore, robust and adaptive planning algorithms are mandatory.

The mainly addressed products to be disassembled within the regarded use-case are two kinds of electric motors for automotive applications. One is a starter motor for combustion engines and the other one is a motor which is used for different auxiliary tasks such as window lifting or the actuation of wipers. In Fig. 1 some of the motor derivate are shown. Due to the utilization in different applications within the car, the smaller motor has different kinds of flanges (3) which are varying in shape and size. The disassembly of the motors includes the removal of the screws (4) and the dismantling of housing components (2).

During the disassembly there are process forces occurring. Especially while unscrewing a certain normal force is mandatory to avoid contact loss of the screw driver and the screws. For the development of the clamping system, the disassembly forces and the possible clamping positions have been analyzed. The regard revealed that the mandatory screws are positioned in an offset location from the feasible clamping positions on the housing at the small motor. Therefore, the applied force during unscrewing generates a momentum on the clamped part. The generated torque exceeds the possibilities from a clamping application in a two position grip and a support position closer to the force vector stemming from the unscrewing process is mandatory. Therefore, the special novelty in this development is the utilization of a supportive, third form clamping system which can be moved to an adequate position in order to cope the process forces of the disassembled part. Since there are different motor types being processed on the clamping system, it needs to adapt individually to the motor type because of the processed part derivatives of the smaller motor. This requires a modification of the support system which is realized by a gantry system.

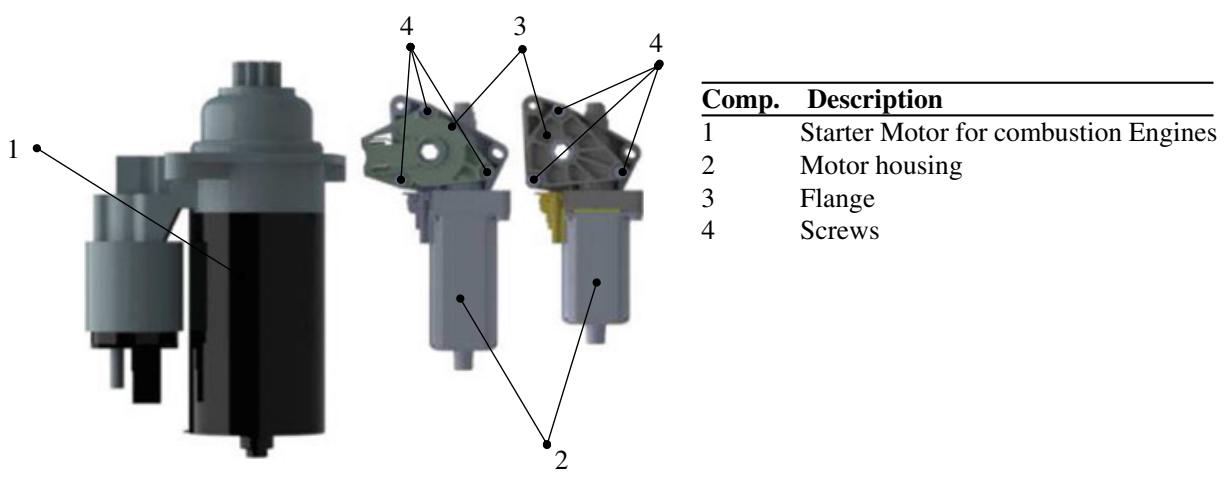

Fig. 1 Different kinds of addressed electric motors 


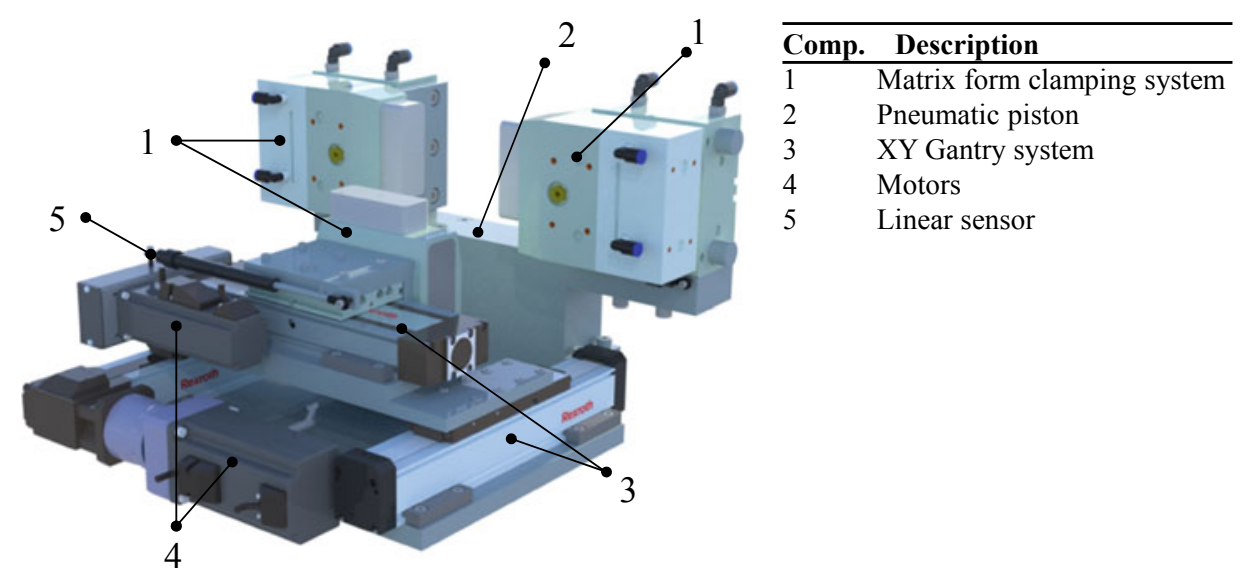

Fig. 2 CAD model of the clamping device for disassembly in remanufacturing applications

\subsection{Concept Proposal}

Figure 2 shows the CAD model of the system. It consists of three matrix pin clamping elements (1), which can be pneumatically locked. Those are the adaptive clamping units and they consists of several metal pins on top of a spring each. By pushing an arbitrary shape onto the pin surface, the negative contour is formed. After pneumatic actuation, the pins are held in place and are not pushed back by the spring. Thus, it is possible to generate form closure independent from the shape and condition of the part. The clamping force is generated by a pneumatic piston (2), actuating one of the three clamping elements against a second, fixed one. The third clamping unit is located on a XY Gantry system (3) in such a form, that it is possible to reconfigure the clamping system to different parts by moving the clamping elements. The motors for the actuation of the gantry system (4) are arranged in such a way that disturbing volume in the clamping area is avoided. Using linear sensors (5), the position of the clamping devices can be detected. The selection of an appropriate clamping orientation and position of the parts is part of the research project, but not of this contribution.

\section{Prototype Clamping System}

For the verification of the approach, a functional prototype is built and described in the following. The prototype uses the same pin clamping elements and the generation of the clamping force is likewise in a pneumatic fashion. At the same time, the gantry system is not used, but the system can be manually configured towards the motor derivate by placing the vertically oriented pin clamping element on bolts. Figure 3 shows an image of the prototype. 


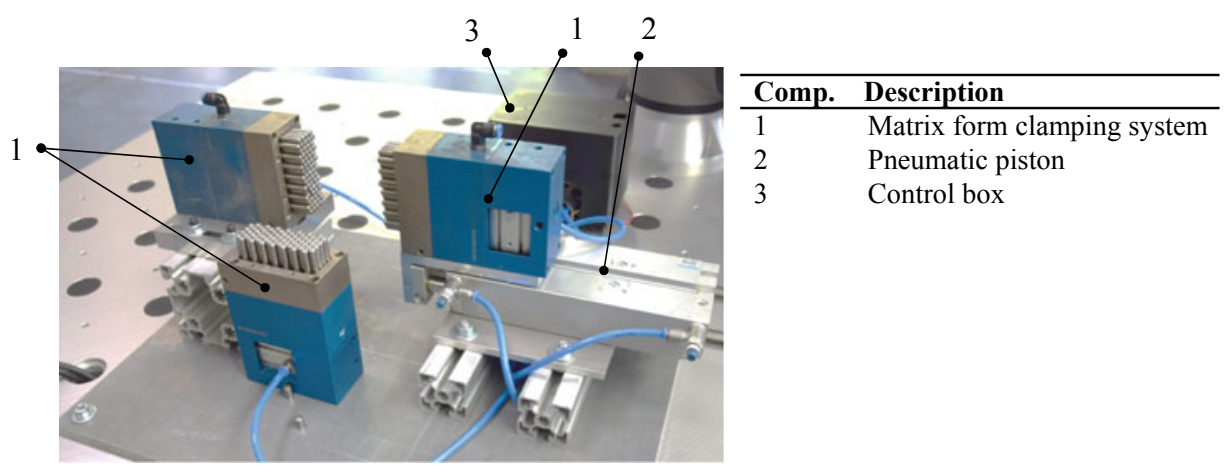

Fig. 3 Prototype system of a clamping device for disassembly in remanufacturing applications

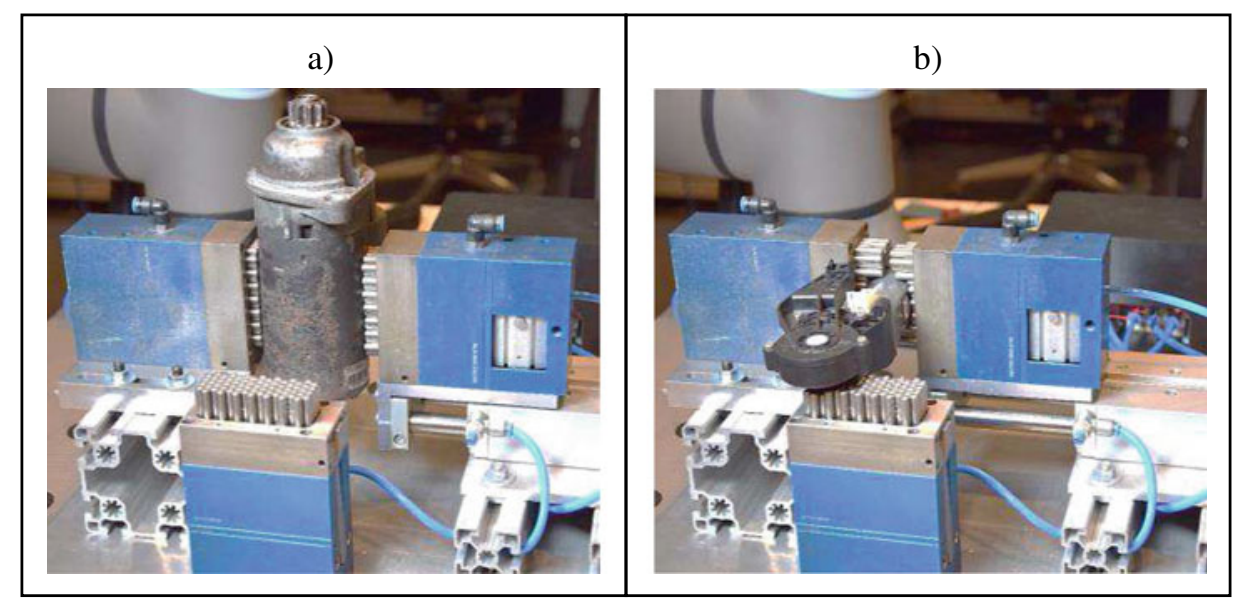

Fig. 4 Depiction of clamping results

The clamping device is faced with the task of clamping both different motor types and therefore setting a corresponding configuration. Afterwards there are screws being removed and the utilized components thereby proven for the capability of withstanding the process forces. Figure 4. shows the clamping of the different motors in comparison. In both cases, the motor is being clamped securely and the components withstand the process forces during disassembly. 


\section{Conclusion and Future Work}

In this contribution, the results of the development of a clamping device for applications in disassembly for remanufacturing has been presented. The requirements emerging from the remanufacturing application have been summarized and respected in the development. The prototypical realization of a comparable module has been shown. The conducted tests verify the approach and the conceptual result. The special novelty of the clamping system is the adaptation of the support position with regard to the disassembly for remanufacturing operations of electric motors at their after-life stage. For future examinations, the presented clamping system needs to be built up to the final expansion stage. Additionally, there are optimization methodologies required for the configuration of the equipment. With adapted methodologies it is possible to identify ideal clamping positions for subsequent processes such as unscrewing or handling tasks.

Acknowledgements The authors would like to express their appreciation to all industry and research partners for supporting the project "AgiProbot". The project is funded by the Carl Zeiss Foundation.

\section{References}

1. Bakker, O., Papastathis, T., Popov, A., et al.: Active fixturing: literature review and future research directions. Int. J. Prod. Res. 51, 3171-3190 (2013)

2. Brost, R., Peters, R.: Automatic design of 3-D fixtures and assembly pallets. Int. J. Robot. Res. 17, 1243-1281 (1998)

3. D'Adamo, I., Rosa, P.: Remanufacturing in industry: advices from the field. Int. J. Adv. Manuf. Technol. 86, 2575-2584 (2016)

4. Graham, I., Goodall, P., Peng, Y., et al.: Performance measurement and KPIs for remanufacturing. J. Remanufacturing 5(10), 2210-2227 (2015)

5. Heinrich, B., Linke, P., Glöckler, M.: Grundlagen Automatisierung. Springer Fachmedien Wiesbaden, Wiesbaden (2020)

6. Jonsson, M., Kihlman, H., Ossbahr, G.: Coordinate controlled fixturing for affordable reconfigurable tooling. In: Proceedings of the 2nd CIRP Conference on Assembly Technologies and Systems, vol.1, pp. 1-11 Elsevier B.V, Amsterdam (2008)

7. Kaya, N.: Machining fixture locating and clamping position optimization using genetic algorithms. Comput. Ind. 57, 112-120 (2006)

8. Liam-An Innovation Story. https://www.apple.com/environment/pdf/Liam_white_paper_ Sept2016.pdf. Last accessed 17 Dec 2020

9. Menassa, R., DeVries, W.: Optimization methods applied to selecting support positions in fixture design. J. Eng. Ind. 113, 412-418 (1991)

10. Nave, M.: Beitrag zur automatisierten Demontage durch Optimierung des Trennprozesses von Schraubenverbindungen. Doctoral Thesis, Universität Dortmund (2003)

11. Peeters, J., Vanegas, P., Mouton, C., et al.: Tool design for electronic product dismantling. In: The 23rd CIRP Conference on Life Cycle Engineering. Procedia CIRP, vol. 48, pp. 466-471. Elsevier B.V, Amsterdam (2016) 
12. Remanufacturing Market Study, For Horizon. https://www.remanufacturing.eu/assets/pdfs/ remanufacturing-market-study.pdf (2020). Last accessed 17 Dec 2020

13. Tolio, T., Bernard, A., Colledani, M., et al.: Design, management and control of demanufacturing and remanufacturing systems. CIRP Ann. 66(2), 585-609 (2017)

14. Velíšek, K., Košt’ál, P., Zvolenský, R.: Clamping Fixtures for Intelligent Cell Manufacturing. Springer, Berlin (2008)

15. Vongbunyong, S., Chen, W.: Disassembly Automation: Automated Systems with Cognitive Abilities. Springer Cham, Heidelberg (2015)

16. Wegener, K., Chen, W., Dietrich, F., et al.: Robot assisted disassembly for the recycling of electric vehicle batteries. In: The 22nd CIRP conference on Life Cycle Engineering. Procedia CIRP, vol. 29, pp. 716-721. Elsevier B.V, Amsterdam (2015)

Open Access This chapter is licensed under the terms of the Creative Commons Attribution 4.0 International License (http://creativecommons.org/licenses/by/4.0/), which permits use, sharing, adaptation, distribution and reproduction in any medium or format, as long as you give appropriate credit to the original author(s) and the source, provide a link to the Creative Commons license and indicate if changes were made.

The images or other third party material in this chapter are included in the chapter's Creative Commons license, unless indicated otherwise in a credit line to the material. If material is not included in the chapter's Creative Commons license and your intended use is not permitted by statutory regulation or exceeds the permitted use, you will need to obtain permission directly from the copyright holder.

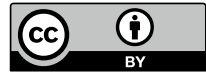

